circulating immune complexes seems the most likely explanation. We believe that this is the first case of pyoderma gangrenosum to occur after elective surgery. It highlights the importance of early clinical diagnosis in a condition that is usually highly amenable to treatment.

1 Powell FC, Schroeter AL, Su WPD, Perry HO. Pyoderma gangrenosum: a review of 86 patients. Qf Med 1985;55:173-86.

2 Brunsting LA, Goeckerman WH, O'Leary PA. Pyoderma (ecthyma) gangrenosum: clinical and experimental observations in five cases occurring in adults. Archives of Dermatology and Syphilology 1930;22:655-80.

3 Johnson RB, Lazarus GS. Pulse therapy, therapeutic efficiency in the treatment of pyoderma gangrenosum. Arch Dermatol 1982;118:76-84

4 Finkel SI, Janowitz HD. Trauma and the pyoderma gangrenosum of inflammatory bowel disease. Gut 1981;22:410-2.

5 Powell FC, Schroeter AL, Perry HO, Su WPD. Direct immunofluorescence in pyoderma gangrenosum. Br f Dermatol 1983;108:287-93.

(Accepted 8 fanuary 1986)

University Department of Surgery, Clinical Sciences Centre, Northern General Hospital, Sheffield S5 7AU

A J CARR, MB, CHB, lecturer in surgery

R C PERCIVAL, FRCS, lecturer in surgery

K ROGERS, MSC, FRCS, consultant and senior lecturer in surgery

Department of Dermatology, Royal Hallamshire Hospital, Sheffield

C T HARRINGTON, MD, MRCP, consultant dermatologist

Correspondence to: Dr Carr.

\section{Meningitis and pneumonia due to novel multiply resistant pneumococci}

Multiply resistant pneumococci associated originally with nosocomial infection ${ }^{1}$ and more recently with community acquired disease ${ }^{2}{ }^{3}$ have been characterised by resistance to $\beta$ lactam antibiotics in addition to other agents. We report the isolation of novel multiply resistant pneumococci showing sedimentation rate $67 \mathrm{~mm}$ in first hour. A pneumococcus with the resistance pattern found in case 1 was isolated from the blood but was unavailable for serotyping. The patient improved with benzylpenicillin. We discovered later that he had received co-trimoxazole during the week before admission. Four children attending the same crèche were examined for nasopharyngeal carriage of resistant pneumococci (table).

Case 3-A 46 year old white man suffering from multiple myeloma was admitted to the Johannesburg Hospital in October 1984 with signs and symptoms of pneumonia. Blood culture taken on admission grew Str pneumoniae serotype 6B showing the same resistance pattern and minimum inhibitory concentrations of drugs as in the other two cases. He responded to benzylpenicillin. Nasopharyngeal swabs were taken from 17 adult patients and staff at the convalescence home where he lived (table)

Case 4-A 2 year old black boy was admitted to the Baragwanath Hospital, Soweto, in December 1985 . He was feverish $\left(38^{\circ} 9^{\circ} \mathrm{C}\right)$ and showed clinical and radiological signs of pneumonia. A pneumococcus (serotype 14) isolated from blood culture showed the same resistance pattern as in cases 1-3. His mother disclosed that for five days before admission he had been given erythromycin ( $250 \mathrm{mg}$ thrice daily) prescribed for a toe infection. Resistant pneumococci wer not isolated from nasopharyngeal swabs from two other children in the household (table).

\section{Comment}

The emergence of community acquired nasopharyngeal and clinical isolates of pneumococci resistant to tetracycline, erythromycin, clindamycin, and co-trimoxazole but susceptible to benzylpenicillin is reported for the first time. Multiple resistance in Str pneumoniae with more than three antimicrobial agents has to date been associated with resistance to $\beta$ lactam antibiotics. All three children reported here gave a history of prior treatment with antimicrobial agents to which the pneumococci were resistant. A relation between exposure to antibiotics and nasopharyngeal carriage of penicillin resistant pneumococci has been described in hospitalised patients.

The strains noted here are not likely to pose therapeutic problems for serious pneumococcal infections requiring admission to hospital. The presence of these organisms does, however, demand urgent consideration of resistant organisms in the management of community acquired pneumococcal diseases such as otitis media and sinusitis, for which erythromycin and co-trimoxazole are often prescribed.

We thank Professor Robert Austrian, of the University of Pennsylvania, for subtyping of isolates.

Nasopharyngeal carriage of multiply resistant pneumococci

\begin{tabular}{lcccc}
\hline & $\begin{array}{c}\text { No of subjects } \\
\text { tested }\end{array}$ & $\begin{array}{c}\text { No carrying multiple resistant } \\
\text { strains }\end{array}$ & Serotypes & \% Carriage \\
\hline Day care centre 1* & 29 & 2 & $14+19 \mathrm{~F}$ & $6 \cdot 9$ \\
Day care centre $2 \dagger$ & 4 & 2 & $14+14$ & $50 \cdot 0$ \\
Convalescence home & 17 & & & \\
Private household $\oint$ & 2 & & & \\
\hline
\end{tabular}

*Case 1 attended day care centre $1 . \quad \ddagger$ Case 3 lived in convalescence home

tCase 2 attended day care centre 2 . lCase 4 came from this household.

susceptibility to $\beta$ lactam antibiotics but resistance to tetracycline, clindamycin, erythromycin, and co-trimoxazole.

\section{Case reports}

Case 1-A 15 month old white boy was admitted to the Johannesburg Hospital in September 1984 with a one day history of lethargy and vomiting. He was feverish and drowsy with pronounced neck stiffness. Lumbar puncture yielded cerebrospinal fluid containing $1260 \times 10^{6}$ neutrophils, $44 \times 10^{6}$ lymphocytes, and $0.38 \mathrm{~g}$ protein per $\mathrm{l}$; glucose $4.4 \mathrm{mmol} / \mathrm{l}(79.3 \mathrm{mg} / 100 \mathrm{ml})$; and chloride 125 $\mathrm{mmol}(\mathrm{mEq}) / \mathrm{l}$. Staining of the fluid disclosed Gram positive diplococci resembling pneumococci, and Streptococcus pneumoniae serotype 14 (antipneumococcal serum, Statens Seruminstitut, Copenhagen) was subsequently isolated. The organism was susceptible to benzylpenicillin but resistant to tetracycline, erythromycin, and clindamycin by disc susceptibility testing (Mastring-S, Mast Laboratories Ltd, UK). Minimum inhibitory concentrations using the agar dilution method ${ }^{4}$ (with Columbia agar (Oxoid, Basingstoke) as the base) were: penicillin $7.0 \mu \mathrm{g} / \mathrm{l}$; tetracycline $4.0 \mathrm{mg} / 1$; and erythromycin, clindamycin, and cotrimoxazole $>8 \mathrm{mg} / \mathrm{l}$. The patient responded to initial treatment with benzylpenicillin and chloramphenicol, which was subsequently changed to benzylpenicillin alone. He had had a dose of tetracycline syrup eight weeks before admission. The table gives the results of nasopharyngeal swabs taken from 29 children from the same crèche.

Case 2-This 20 month old white boy was also admitted to the Johannesburg Hospital in September 1984. He had a two week history of fever and coughing and on the day of admission had a convulsion accompanied by a fever of $38.9^{\circ} \mathrm{C}$, right sided otitis media, and radiologically confirmed left upper lobe pneumonia. Blood leucocyte count was $50.2 \times 10^{\circ} / \mathrm{l}$, haemoglobin concentration $9.8 \mathrm{~g} / \mathrm{l}$, and
1 Jacobs MR, Koornhof $\mathrm{HJ}$, Robins-Browne RM, et al. Emergence of multiply resistant pneumococci. N Englf Med 1978;299:735-40.

2 Radetsky MS, Istre GR, Johansen TI, et al. Multiply resistant pneumococcus causing meningitis; its epidemiology within a day care centre. Lancet 1981;ii:771-3.

3 Simberkoff MS, Richmond A, Lukasjewski $M$, et al. Isolation of multiply antibiotic-resistant pneumococci-New York: $M M W R$ 1985;34:545-6.

4 Jacobs MR, Gaspar MN, Robins-Browne RM, Koornhof $H J$. Antimicrobial susceptibility testing of pneumococci. I Antimicrob Chemother 1980;6:53-64.

5 Robins-Browne RM, Kharsany ABM, Koornhof HJ. Antibiotic-resistant pneumococci in hospitalized children. $\mathcal{f} \mathrm{Hyg}(\mathrm{Camb})$ 1984;93:9-16.

(Accepted l fanuary 1986)

Emergent Pathogen Research Unit of the South African Medical Research Council, Department of Medical Microbiology, School of Pathology of the University of the Witwatersrand and the South African Institute for Medical

Research, Johannesburg

KEITH P KLUGMAN, MB, PHD, senior registrar

HENDRIK J KOORNHOF, MB, FRCPATH, professor of medical microbiology

VALERIE KUHNLE, MT, (CLIN PATH), chief technologist

STEVEN D MILLER, MB, MRCPATH, consultant

PHILIP J GINSBURG, $\mathrm{MB}, \mathrm{BCH}$, senior registrar

ALFRED C MAUFF, MB, FFPATH, consultant

Correspondence and requests for reprints to: Dr K P Klugman, Department of Medical Microbiology, School of Pathology, South African Institute for Medical Research, PO Box 1038, Johannesburg, South Africa. 